\title{
Level of Healthcare Providers' Preconception Care (PCC) Practice and Factors Associated with Non-Implementation of PCC in Hawassa, Ethiopia
}

\author{
Andargachew Kassa ${ }^{1 *}$, Sarie Human ${ }^{2}$, Hirut Gemeda ${ }^{3}$
}

\section{OPEN ACCESS}

Citation: Andargachew Kassa, Sarie Human, Hirut Gemeda. Level of Health Care Providers' Preconception Care (PCC) Practice and Factors Associated with NonImplementation of PCC in Hawassa, Ethiopia. Ethiop J Health Sci. 2018; 29 (1):903.

doi:http://dx.doi.org /10.4314/ejhs.v29i1.12 Received: August 06, 2018

Accepted: September 21, 2018

Published: January 1, 2019

Copyright: (C) 2018 Andargachew Kassa, et al. This is an open access article distributed under the terms of the Creative Commons Attribution License, which permits unrestricted use, distribution, and reproduction in any medium, provided the original author and source are credited.

Funding: Bona District Health Bureau and Abem private clinic.

Competing Interests: The authors declare that this manuscript was approved by all authors in its form and that no competing interest exists.

Affiliation and Correspondence:

${ }^{1}$ College of Medicine and Health

Sciences Hawassa University, Ethiopia

${ }^{2}$ Department of Health Studies University of South Africa, Pretoria, South Africa

${ }^{3}$ Department of Midwifery College of Medicine and Health Sciences Hawassa University, Ethiopia

*Email: akandkassa@gmail.com

\begin{abstract}
BACKGROUND: Healthcare providers (HCPs) are at the forefront of screening and identifying preconception risk factors leading to adverse pregnancy outcomes (APOs). In Ethiopia, there is no published study that assessed the status of the implementation of PCC. This is a study conducted with the aim of determining the level of HCP's PCC practice and factors associated with non-implementation of PCC.

METHODS: This institution based cross-sectional studyconducted among HCPs working in public health institutions (PHI) of Hawassa. The data was collected using a validated instrument called 'Andarg-Ethio PCC-KAPQuestionnaire'. A ltistage sampling was applied to draw a sample of 634 HCPS. The data were analyzed using SPSS software, version 20. Descriptive statistics and binary as well as multiple logistic regression analysis models were used to determine the cruds and adjusted odds ratios.

RESULTS: Out of the total study participants, 84.7\%(537) were found not totally practising PCC. Those HCPs who do not screen their clients' reproductive life plan (RPL) had 7 times higher odds of not practising PCC (AOR=7.2 95\% C.I. 3.6- 14.5), whereas those HCPs with poor PCC knowledge had 4 times higher odds of not practising PCC (AOR=4.4, 95\% C.I. 2.5-7.6).

CONCLUSION: The findings of this study demonstrated the absence of standardized and consistent PCC practice which indicates that PCC is not well introduced to the area. Developing of PCC policy and guidelines plus training of HCPs are recommended.

KEYWORDS: Preconception care, knowledge, attitude, practice, health care providers

\section{INRODUCTION}

Nearly all of the adverse pregnancy outcomes (APOs) are reported from low-income countries. For instance, the vast majority $(99 \%)$ of all the maternal death, more than $60 \%$ of preterm birth, $96.5 \%$ of LBW ), $98 \%$ of stillbirth (1-3) and $99 \%$ of neonatal death (4) are happening in developing countries especially in Sub-Saharan Africa, where Ethiopia is located.
\end{abstract}


Most of the factors contributing to APO are avoidable (5). The most globally known APO preventive interventions include antenatal care, institutional delivery and postnatal care (6, 7). This set of maternal health care services in the past three to four decades were proven effective but could not solve all APOs. With these interventions, the healthcare providers (HCPs) are acting too late after the conception happened and after the woman is aware of her pregnancy $(7,8)$. The first antenatal care visit, unfortunately, happens after the 12 weeks of gestation. The early gestational weeks are the missed periods which are critical to the development of the fetal organs. The irreversible and major damages happening to the fetus occur during this critical period. That is why the existing interventions are too late to solve APOs happening during this critical period. In addition, these interventions are not totally designed to target on preconception risk factors leading to the development of APOs happening within the critical period mentioned $(5,8)$.

The lately identified but effective evidencebased intervention among the continuum of the spectrum of the maternal and child health services is preconception care (PCC) $(7,9)$. The CDC defined PCC as "... a set of interventions that aim to identify and modify biomedical behavioral and social risks to the women's health or pregnancy outcome through prevention and management." (8). It is a unique and innovative approach which identifies couples contemplating pregnancy before conception to modify biomedical, behavioral, social and environmental risk factors leading to APO $(5,10)$. Except for its proven benefits, so far, there is no existing evidence depicting the disadvantage of PCC (11). Cognizant of this fact, the CDC in 2006 and the WHO in Novembers 2012 gave a recommendation for the implementation of preconception and interconception care interventions as part of the overall national and international health system (5).

A policy document analysis conducted as part of this research project demonstrated lack of a policy document guiding the implementation of PCC in Ethiopia (12). In addition, there is no published evidence that assessed the status of HCPs PCC practice and factors associated with their PCC practice. This study, therefore, intended to determine the level of HCP's PCC practice and factors associated with the non-implementation of PCC. Determination of the level of HCP's PCC practice and its key associated factors will lay a baseline finding as an input to health policy adjustment and future research.

\section{METHODS}

This is a crosssectional study conducted among HCPs working in public health institution (PHI) within of Hawassa. Hawassa City administration is one of the administrative Zones of the Southern Nations Nationalities and Peoples Region (SNNPRS) of Ethiopia. Within the city are 2 Public Hospitals (PHO), 9 Public Health Centres (PHC) and 17 Public Health Posts (PHP). Of the PHOs, one is University Teaching Hospital (HU$\mathrm{CSH}$ ) serving more than 10 million people. The city is the Capital of SNNPR located $275 \mathrm{~km}$ south of Addis Ababa. During the study period, May 2017, there were a total of 1239 HCPs working in the PHIs of the city (HCA 2016).

We drew the minimum sample by using a single population proportion formula and multistage sampling technique. During the computation, we fixed $\boldsymbol{\alpha}$ at $0.05,95 \%$ Confidence Interval (CI), and design effect of 2 . Since we could not get similar research conducted using the same validated instrument in similar sociodemographic context, we preferred to assume $50 \%$ proportion. Considering a $10 \%$ non-response rate, the final minimum size was found to be 647 HCPs. The participants of the study were randomly selected proportional to their profession. At the first stage, using lottery method, the healthcare facilities were selected. At the second level, participants were selected by using systematic random sampling technique.

A structured self-administered instrument used for this study is titled 'Andarg-Ethio PCCKAP-Questionnaire for HCPS. This tool was originally developed by the principal investigator. The composite content validity index (CVI) of the instrument was $92.4 \%$. This validated instrument

DOI: http://dx.doi.org/10.4314/ejhs.v29i1.12 
was then pretested on 65 HCPs working in PHIs of a nearby city called Shashemene. The instruments internal consistency was measured for two sets of questionnaires that measured the attitude and practice. The Cronbach's $\alpha$ test results were 0.725 and 0.945 respectively. The questionnaire was first prepared in English and then translated into Amharic. It was then translated back into English (12)

Those HCPs found to practice above the mean score were taken as "HCPs with good PCC practice" and those who scored below the mean as "HCPs with poor PCC practice". To further describe the level of providers' PCC practice, we classified those who scored $<50 \%$ of items measuring PCC practice as practitioners demonstrating 'low level of PCC practice'. The remaining ones who scored between 50\%-75\% and those scored $>75 \%$ were categorized as providers with a medium and higher level of PCC practice respectively.

The cleaned data were checked, coded and entered into SPSS version 20. The bivariate analysis was done one by one to determine the crude odds ratio (COR) for each variable with $95 \%$ CI. Vriables with their COR $<0.25$ were aken to multiple logistic regression analysis. Goodness of fit for the model was also tested by diagnosing correctness of the formulation of the models by using Hosmer-Lemeshow test.

This study was approved by the Institutional Review Board of the College of Medicine and Health Sciences of Hawassa University (IRB No: 068/09). All the study participants were also given an informed consent form to voluntarily participate in the study.

\section{RESULTS}

A total of 634 HCPs participated in this study. This makes the response rate $98.0 \%$. More than half (61.4\%) were women. More than half (59.6 $\%$ ) of the study participants were between the age group of 26-30 years. Nurses were HCPs constituting $66.9 \%$ of the study population. All the health extension who workers participated in this study were basically nurses working in the PHCU called Health Posts (Table 1).

Table 1: Socio-demographic characteristics of health care Providers working in public health
Institutions of Hawassa ( $\mathrm{n}=634), 2017$, South Ethiopia.

\begin{tabular}{|c|c|c|}
\hline \multirow{2}{*}{$\begin{array}{l}\text { Socio-demographic } \\
\text { Characteristics }\end{array}$} & \multicolumn{2}{|c|}{ Total } \\
\hline & Frequency & Percent \\
\hline \multicolumn{3}{|l|}{ Sex } \\
\hline Female & 389 & 61.4 \\
\hline Male & 245 & 38.6 \\
\hline \multicolumn{3}{|l|}{ Age } \\
\hline 20-25 Years & 178 & 28.1 \\
\hline 26-30 Years & 378 & 59.6 \\
\hline 31-35 Years & 55 & 8.7 \\
\hline$>$ or $=36$ & 23 & 3.6 \\
\hline \multicolumn{3}{|l|}{ Marital status } \\
\hline Single & 322 & 50.8 \\
\hline Married & 300 & 47.3 \\
\hline Divorced & 10 & 1.6 \\
\hline Widowed & 2 & .3 \\
\hline \multicolumn{3}{|l|}{ Profession } \\
\hline Nurse & 424 & 66.9 \\
\hline Health & 62 & 9.8 \\
\hline \multirow{2}{*}{\multicolumn{3}{|c|}{ Extension }} \\
\hline \multicolumn{2}{|l|}{ Worker } & \\
\hline Midwifery & 57 & 9.0 \\
\hline Medical Doctor & 51 & 8.0 \\
\hline Public Health & 40 & 6.3 \\
\hline Officer & & \\
\hline \multicolumn{3}{|l|}{ Education } \\
\hline Diploma & 408 & 64.4 \\
\hline B.Sc. & 187 & 29.5 \\
\hline M.Sc. & 5 & .8 \\
\hline GP/MD & 28 & 4.4 \\
\hline Specialty/MD & 6 & .9 \\
\hline \multicolumn{3}{|l|}{ Year of experience } \\
\hline$<5$ & 381 & 60.1 \\
\hline$>$ or $=5$ & 253 & 39.9 \\
\hline \multicolumn{3}{|l|}{ Monthly salary in birr } \\
\hline$<4000$ & 312 & 49.2 \\
\hline $4000.0-4791.3$ & 179 & 28.2 \\
\hline$>4791.3$ birr & 143 & 22.6 \\
\hline \multicolumn{3}{|l|}{ Religion } \\
\hline Protestant & 396 & 62.5 \\
\hline Orthodox & 185 & 29.2 \\
\hline Muslim & 32 & 5.0 \\
\hline Catholic & 15 & 2.4 \\
\hline Other & 6 & 0.9 \\
\hline
\end{tabular}

Nearly all,537(84.7\%) never provided a single component of PCC. Very few, 97(15.3\%), of the practitioners were found practicing PCC. A focused analysis, on HCPs who claimed to practice PCC, also demonstrated the levels to which providers are practicing PCC. Among those

DOI: http://dx.doi.org/10.4314/ejhs.v29i1.12 
practicing PCC, all ( $\mathrm{n}=97)$ implemented $<50 \%$ of the items measuring PCC practice which is a low level of PCC practice. Thus, there is no HCP categorized neither with a higher nor medium level of PCC practice (Figure 1).

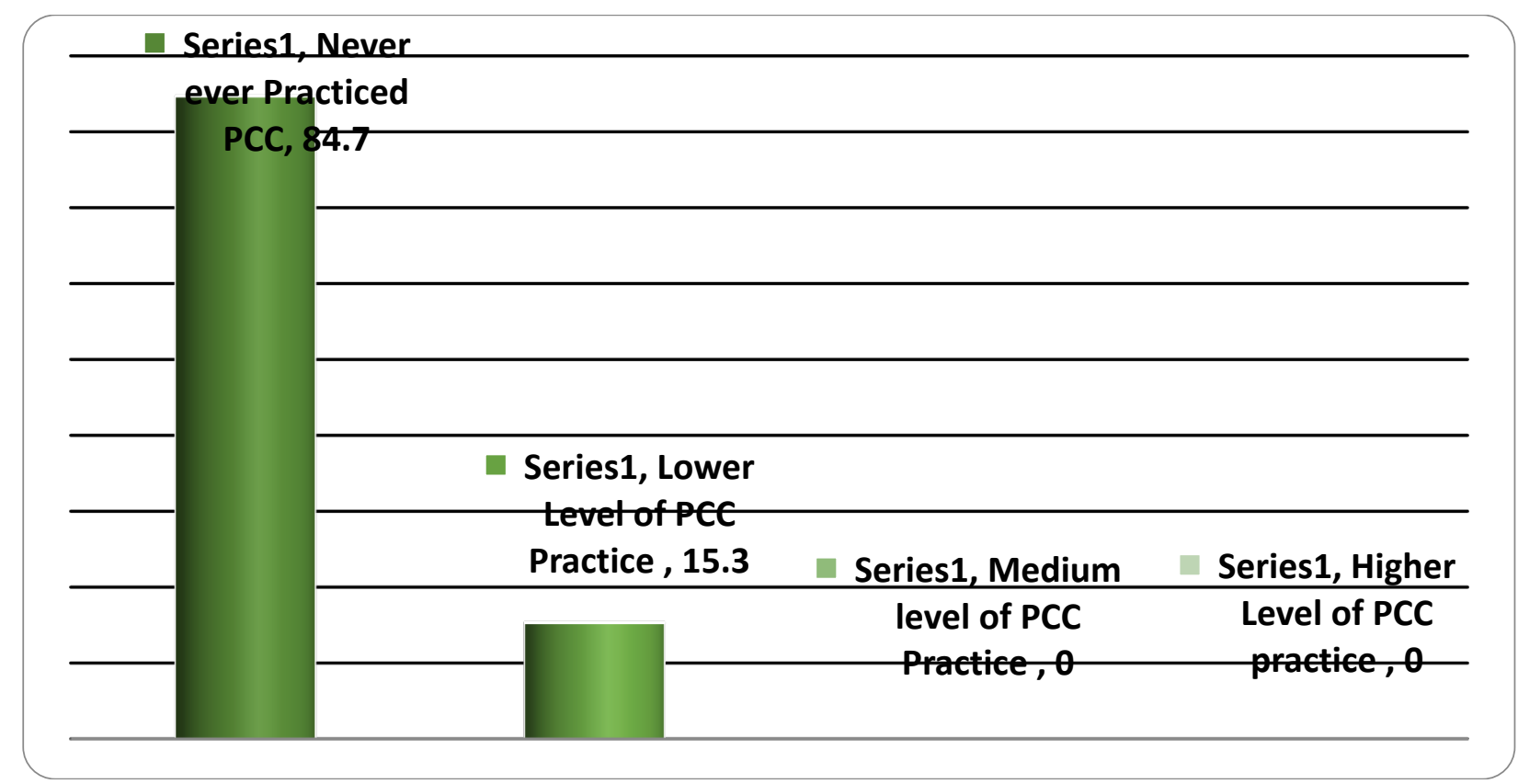

Figure 1: Health professional Practicing PCC in public health institutions of Hawassa (n=634). 2017, South Ethiopia

As shown in Table 2, some of the PCC services were not being practiced. For instance, HCPs did not provide folic acid supplementation for nonpregnant women, and preconception counselling issue regarding environmental hazard were not discussed. The genetic screening test and $\mathrm{HbAlc}$ tests were not totally practiced (Table 2).

Table 2: Selected PCC items not practiced by the health care providers working in public health institutions of Hawassa. 2017, Hawassa, Southern Ethiopia

\begin{tabular}{lrr}
\hline Status of HCP's Practice & Frequency & Percent \\
\hline - Counselling on preconception folic acid supplementation & 0 & $0 \%$ \\
- Counselling about the importance of environmental hazard and toxins & 0 & $0 \%$ \\
- Importance of partner involvement in PCC & 0 & $0 \%$ \\
- Assessment of patient's e exposure with environmental hazard \& toxins & 0 & $0 \%$ \\
- Assessment of history of dental care or check-ups & 0 & $0 \%$ \\
- Preconception folic acid supplementation to RH aged clients & 0 & $0 \%$ \\
- Cigarette, alcohol and other substance use cessation & 0 & $0 \%$ \\
- Genetic screening tests & 0 & $0 \%$ \\
- Immunizations other than TT Vaccines & 0 & $0 \%$ \\
- Haemoglobin Alc screening for DM patients & 0 & $0 \%$ \\
\hline
\end{tabular}

DOI: http://dx.doi.org/10.4314/ejhs.v29i1.12 
When asked to propose who should provide PCC, the participants of the study chose out of the eight options indicated on the self-administered questionnaire. They were also given the chance to write other than the lists. The study participants did not write anything other than the given options. More than half, (51.9\%), gave their opinion that all health care providers, i.e. medical doctors, nurses, midwives, public health officers and health extension workers should provide PCC. The remaining participants indicated specific healthcare providers (Figure 2).

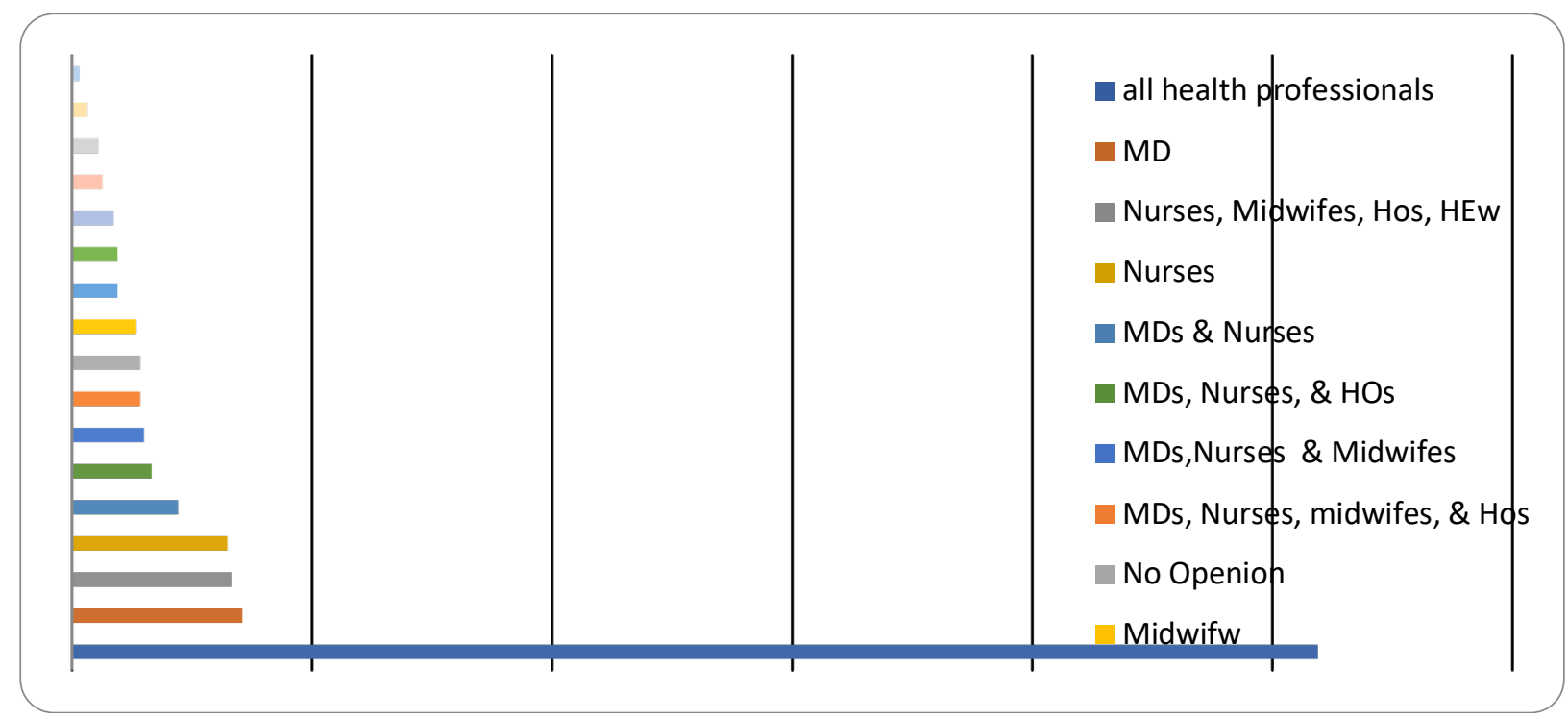

Figure 2: Health Care Providers' opinion on who should give PCC. Hawassa, 2017, South Ethiopia

The likelyhood of non-implementation of PCC was by seven fold higher among those HCPs who did not regularly screen women's intention to pregnancy or their reproductive life plan (RPL) than those regularly screening ( $\mathrm{AOR}=7.295 \%$ C.I. 3.6-14.5). The second most important key predictor found in this study was knowledge. Providers with poor PCC knowledge had the probability of not practicing PCC four times more than those with Good PCC knowledge $(\mathrm{AOR}=4.4, \quad 95 \% \quad$ C.I. 2.5-7.6). Compared to medical doctors, nurses and midwives together had the probability of not completely practicing an element of PCC by more than two times $(\mathrm{AOR}=2.4,95 \%$ C.I. 1.3 - 4.6). The Last factor identified in this study was HCPs perceived expectation on who should provide PCC. Those HCPs who possessed a perceived expectation that 'PCC should be given by selected HCPs' had odds of not totally practicing PCC by two fold more than those who expect that PCC should be given by all HCPs $(\mathrm{AOR}=2.0,95 \%$ C.I. 1.3-3.3) (Table 3).

DOI: http://dx.doi.org/10.4314/ejhs.v29i1.12 
Table 3: Bivariate and multivariate logistic regression analysis depicting predictors of providers PCC practice. 2017, Hawassa, South Ethiopia

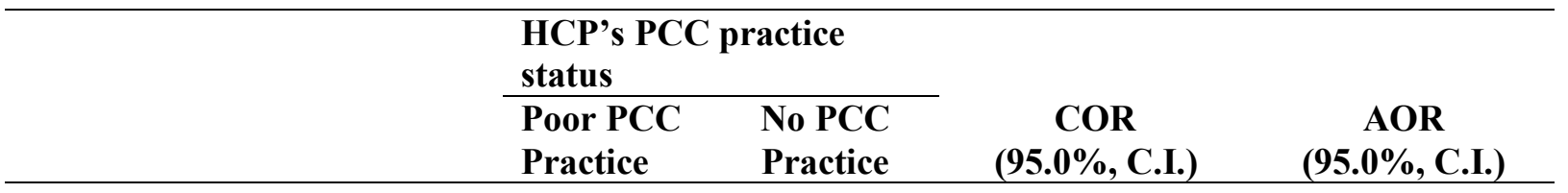

HCP's Knowledge on PCC

\begin{tabular}{cccll} 
Poor PCC Knowledge & 19 & 251 & $3.1(2.1-6.1)^{* * *}$ & $4.4(2.5-7.6)^{* * *}$ \\
\cline { 2 - 5 } & & & & 1 \\
Good PCC knowledge & 78 & 286 & $1^{\S}$ & 1 \\
\hline HCP screens client's RPL & & & & \\
Not screening & 10 & 221 & $6.1(3.1-12.0)^{* * *}$ & $7.2(3.6-14.5)^{* * *}$ \\
Regularly screening & 87 & 316 & 1 & 1 \\
\hline Who should give PCC? & & & & \\
Selected HCP's & 34 & 271 & $1.9(1.2-3.0)^{*}$ & $2.0(1.3-3.3)^{*}$ \\
All HCP's & 63 & 266 & 1 & 1 \\
\hline
\end{tabular}

Health Care Providers

PHOs \& HEW's

Nurses and Midwifes

Medical Doctors

\begin{tabular}{lcll}
18 & 84 & $1.8(0.8-3.9)$ & $1.6(0.6-3.5)$ \\
\hline 65 & 416 & $2.7(1.4-4.7)$ & $2.4(1.3-4.6)^{*}$ \\
\hline 14 & 37 & 1 & 1
\end{tabular}

$1^{\S}=$ Reference category, ${ }^{*}=\mathrm{PV}<0.05, * *=\mathrm{PV}<0.001, \quad * * *=\mathrm{PV}<0.0001, \mathrm{COR}=$ Cruds Odds Ratio AOR=Adjusted Odds Ratio, $\mathrm{CI}=$ confidence interval

\section{DISCUSSION}

The findings of this study indicated that almost all HCPs were not totally implementing PCC (85\%). The remaining HCPs claiming to practice $(15 \%)$ were caring out it 'sometimes' and 'not totally'. As indicated in Table 3, there were components of PCC that were not provided by the HCPs.

These findings, compared to reports from other studies, are evidence showing the absence of the service in the study area. For instance, a crosssectional study from Nevada reported that $43 \%$ of the HCPs were providing PCC (13). The survey from Ontario, Canada, report showed that $95.8 \%$ of the family physicians were providing the service. However, $20 \%$ of them indicated conducting PCC rarely (14). The crosssectional study from Iran reported HCPs 'practicing PCC fairly' range from 25\% - 47.6\% (15). As another study report from the Netherlands, $27 \%$ of the general practitioners and
$20 \%$ of the midwives were giving PCC within two months proceeding the date the data was collected (16). The PCC practice reported from these and other countries included almost all components of the PCC with slight variations. Those PCC service-components not totally provided in this study area are all given by the stated countries (13-15, 17).

Almost similar with the findings of this study, the survey report from the El-mania Governorate of Egypt did not report any "good $P C C$ " provided by the $\operatorname{HCPs}(18)$. As to this report, $25 \%$ of the HCPs never practiced a component of PCC. In case of this study, it was even much higher $(84.7 \%)$. Three forth $(75 \%)$ of the El-mania HCPs were found at least practicing PCC even though it was poor or at a substandard level. In this study, in contrast to the Egypt practitioners, only $15.3 \%$ of HCPs were identified providing a substandard or poor PCC practice).

A complete or good PCC is a care addressing all the essential elements of PCC. These elements

DOI: http://dx.doi.org/10.4314/ejhs.v29i1.12 
are categorized into three main and sequential steps. The first is preconception assessment and risk screening, preconception counselling, and prevention and management of identified risk factors. A PCC which does not include all the essential elements of PCC are substandard, inadequate or poor PCC care. The care should also be given regularly to all the eligible clients before conception $(5,8)$. The type of service identified in this study is totally not a full packaged care. That means, a care that includes all the essential elements. Nevertheless, the existence of the practice in its weakened form may create a ground for further enhancement of the services. The reason for the observed variation may be explained by the policy frameworks guiding the practice of PCC implementation in each country (5). Unlike the other countries, PCC is not yet supported and guided by a policy framework designed by the Ethiopian Ministry of Health (12). In agreement with this, one study conducted in Adama, Ethiopia, reported the absence folic acid supplementation during the preconception period due to lack of policy makers awareness (19).

The most important factor identified using a multivariate logistic regression model was the HCPs RPL screening practice. HCPs who are not regularly screening the RPL of the client had a likelihood of not practicing or not implementing PCC by seven fold higher than those who regularly screen RPL. Regularly conducting RPL is highly recommended and is the gateway of provider-initiated PCC. RPL may be screened for various medical reasons other than PCC (20). Despite the available recommendation and its observed effect, in this study, more than one third $(36.4 \%)$ of health professionals have never practiced RPL. Even among those who claimed to practice RPL, all were not practicing it 'oftentimes' or 'always'. Enhancement of RPL with adequate PCC training and institutional reinforcement may help to address all the eligible to get PCC. A single question to screen RPL may help as an entry point to PCC and optimize the feto-maternal health $(10,21,22)$.

This study identified HCPs poor PCC knowledge as another key factor associated with the non-implementation of PCC. The odd of not practicing PCC was four times greater than among HCPs with poor PCC knowledge than HCPs with good PCC knowledge. Various studies conducted on a similar topic identified that HCPs knowledge on PCC is a key determinant factor to providers' PCC practice. It makes sense that HCPs practice what they already thought or knew either from their in-service or pre-service training (23-25). The reason for the identified HCPs poor PCC knowledge may be linked to the absence of in-service and pre-service training on PCC. A policy document analysis and qualitative studies conducted as part of this study identified the fact that there was no PCC policy and PCC guidelines for guiding HCPs practice. In addition, the HCPs training curriculum did not include PCC (12). Knowledge is also one of the most important determinants to HCPs evidence-based practice $(26,27)$.

The HCPs expectation on who should provide PCC is one of the factors associated with providers' non-implementation of PCC. This may be linked with absence of clear job description, absence of facility-based policy and procedural guideline and poor HCPs knowledge about the nature of PCC $(12,16)$. As noted in this study, those who perceived that all HCP should provide PCC were more likely to practice PCC as compared to HCPs with the perception that selected HCPs are responsible. Obstetric care providers claimed that they usually see women with established pregnancy with no chance to provide PCC (28). Others mentioned the presence of other competing demands making their involvement in PCC very unlikely $(29,30)$. This may be the reason to explain the perception held by some of the HCPs that selected HCPs should provide PCC. This finding is consistent with the lack of clear understanding on the question 'Who should provide PCC?'(16). Nevertheless, all HCPs working at the various levels of the healthcare system and providing care to reproductive health of women and men can provide PCC $(5,8,31,32)$.

Compared to medical doctors, nurses and midwives together had nearly two times higher odds of not-implementing PCC. Similar studies could not be found to make a comparison with this result. The variation noted in this study may

DOI: http://dx.doi.org/10.4314/ejhs.v29i1.12 
be linked to providers' previous academic preparation and setups in which these professionals are working. The policy document analysis, however, showed the non-inclusion of PCC in doctors', nurses' and midwives' preservice training curriculums (12). The CDC strongly recommended that all HCPs caring for a woman need to implement the recommended PCC (8). The WHO also indicated the importance of building the capacity of doctors, nurses, midwives and other public health managers to enhance the planning, implementation and monitoring of PCC. This document stressed the need to focus the capacity building on the area of pre-service education (5). Inclusion of PCC in the curriculum of all HCPs pre-service training along with provision of an in-service training may help provide the service to all HCPs caring for the eligible reproductive aged individuals.

The vast majority of the HCPs showed their willingness to incorporate PCC into their daily practice. Nevertheless, out of the total study participants, 537(84.7\%) were found not totally practicing or implementing PCC. Only $15.3 \%$ of the practitioners were found practicing a substandard or low level of PCC.

There are a number of PCC elements never practiced by the HCPs. These include preconception folic acid supplementation, preconception counselling issues regarding environmental hazard and contaminants, preconception genetic screening and testing, preconception HbA1c monitoring for a patient with DM, assessment of the history of dental care or check-ups, and cessation of psychoactive substances such cigarette, alcohol, and other drugs. The overall assessment of the PCC 'implementation' revealed mainly the absence of PCC implementation. Nevertheless, there exists a substandard or poor implementation of PCC by very few HCPs.

This study also identified four key factors predicting the odds of non-implementation of PCC by the HCPs. These were not screening clients' RPL, HCPs' poor PCC knowledge, belonging to the nursing and midwifery professional category, and HCPs' perceived understanding that only selected HCPs should provide PCC.

As per the authors' best systematic literature search, there is no published and unpublished study conducted to assess the practice of PCC and determinants to non-implementation of PCC in Ethiopia. This study, therefore, lays baseline information for determining the levels of HCPs PCC practice and its associated factors. These findings, thus, will be used to compare achievements made by future corrective measures. It also will be used to compare findings of similar researches conducted nationally and internationally. The validated measurement tool used in this study can also be adopted by other researchers to harmonize and facilitate uniform comparison of findings.

Nevertheless, this study, as all other studies, is not without limitations. First, despite the rigorous techniques used to minimize biases, possibilities of recall bias is expected. In addition, as a cross-sectional study, this study assessed the status that happened during the study period.

Provision of pre-service and an in-service PCC training to all health care providers is highly recommended. Next, the issue of developing or adopting a clear PCC policy and guidelines need the prompt action of the ministry of health. Third, the inclusion of a single RPL question in clinical assessment formats may serve as a reminder to all HCPs. Consideration of the aforementioned recommendations may inform the ministry of health and all other concerned parties to commence the introduction or integration of PCC in Ethiopia health system and ultimately assure its sustainable implementation.

\section{ACKNOWLEDGMENTS}

We would like to acknowledge all the survey administrators and supervisors, particularly Mr. Arega Donka. 


\section{REFERENCES}

1. Stanton C, Lawn JE, Rahman H, WilczynskaKetende K, Hill K. Stillbirth rates: delivering estimates in 190 countries. Lancet. 2006;367(9521):1487-94.

2. Blencowe H, Cousens S, Oestergaard MZ, Chou D, Moller AB, Narwal R, et al. National, regional, and worldwide estimates of preterm birth rates in the year 2010 with time trends since 1990 for selected countries: a systematic analysis and implications. Lancet. 2012;379(9832):2162-72.

3. WHO. Maternal, new-born, child and adolescent health:Care of the preterm and/or low-birth weight new-born Geneva, Switzerland: World Health Organization; 2017 [Available-from:

http://www.who.int/maternal_child_adolescen t/t opics/newborn/care of preterm/en/.

4. WHO. World Health Day: Facts and figures from The World Health Report 2005. Geneva, Switzerland: World Health Organization; 2005.

5. WHO. Meeting to develop a Global consensus on preconception care to reduce maternal and childhood mortality and morbidity. Geneva, Switzerland: World Health Organization; 2013.

6. Lawn JE, Kerber K. Opportunity for Africa's newborns: practical data, policy and programmatic support for newborn care in Africa. On behalf of PMNCH UNFPA, UNICEF, USAID, WHO. Jeneva, Published 2006.

7. Dean SV, Lassi ZS, Imam AM, Bhutta ZA. Preconception care: closing the gap in the continuum of care to accelerate improvements in maternal, newborn and child health. Reprod Health. 2014;11 Suppl 3:S1.

8. Johnson K, Posner SF, Biermann J, Cordero JF, Atrash HK, Parker CS, et al. Recommendations to improve preconception health and health care--United States. A report of the CDC/ATSDR Preconception Care Work Group and the Select Panel on Preconception Care. MMWR Recomm Rep. 2006;55(RR-6):1-23.

9. Kerber KJ, de Graft-Johnson JE, Bhutta ZA, Okong P, Starrs A, Lawn JE. Continuum of care for maternal, newborn, and child health: from slogan to service delivery. Lancet. 2007;370(9595):1358-69.

10. CDC. Preconception Health and Health Care: Reproductive Life Plan Tool for Health Professionals. 2010.

11. Braspenningx S, Haagdorens M, Blaumeiser B, Jacquemyn Y, Mortier G. Preconceptional care: a systematic review of the current situation and recommendations for the future. Facts, views \& vision in ObGyn. 2013;5(1):13-25.

12. Biratu AK. Addressing the high adverse pregnancy outcomes through the incorporation of preconception care (PCC) in the health system of Ethiopia [PHD]. Pretoria, South Africa: University of South Africa (UNISA); 2017.

13. Van E. Preconception Care Practices of Health Care Providers in Washoe County, NV: University of Nevada; 2012.

14. Centre BSR. Preconception Health Physician Practices in Ontario. Best Start: Ontario's Maternal, Newborn and Early Child Development Resource Centre. Ontario, Canada; 2009.

15. Bayram R, Ebrahimipour H, Ebrahimi M, Froutani MR, Najafzadeh B: Health care provider s' knowledge, attitude and practice regarding pre-conception care. Journal of Research and Health. 2013;3(8).

16. van Voorst S, Plasschaert S, de Jong-Potjer L, Steegers E, Denktas S. Current practice of preconception care by primary caregivers in the Netherlands. Eur $J$ Contracept Reprod Health Care. 2016;21(3):251-8.

17. Heyes T, Long S, Mathers N. Preconception care: practice and beliefs of primary care workers. Fam Pract. 2004;21(1):22-7.

18. Mosalem FA, Azza A, Tehany MR, Ekbal AE. Awareness of primary health care providers in Elminia Governorate about preconception care, Egipt. El-Minia Medical Bulletin. 2012;23(1):14.

19. Dessie MA, Zeleke EG, Workie SB, Berihun AW. Folic acid usage and associated factors in the prevention of neural tube defects among pregnant women in Ethiopia: cross-sectional

DOI: http://dx.doi.org/10.4314/ejhs.v29i1.12 
study. BMC pregnancy and childbirth. 2017;17(1):313.

20. Coffey K, Shorten A. The challenge of preconception counseling: Using reproductive life planning in primary care. $J$ Am Assoc Nurse Pract. 2014;26(5):255-62.

21. Callegari LS, Aiken AR, Dehlendorf C, Cason $\mathrm{P}$, Borrero S. Addressing potential pitfalls of reproductive life planning with patientcentered counseling. Am J Obstet Gynecol. 2017;216(2):129-34.

22. Liu F, Parmerter J, Straughn M. Reproductive Life Planning: A Concept Analysis. Nurs Forum. 2016;51(1):55-61.

23. Guess K, Malek L, Anderson A, Makrides M, Zhou SJ. Knowledge and practices regarding iodine supplementation: A national survey of healthcare providers. Women Birth. 2017;30(1):e56-e60.

24. Hauser KW, Lilly CM, Frias JL. Florida health care providers' knowledge of folic acid for the prevention of neural tube defects. outh Med J. 2004;97(5):437-9.

25. van Heesch PN, de Weerd S, Kotey S, Steegers EA. Dutch community midwives' views on preconception care. Midwifery. 2006;22(2):120-4.

26. Fleuren M, Wiefferink K, Paulussen $T$. Determinants of innovation within health care organizations: literature review and Delphi study. Int $J$ Qual Health Care. 2004;16(2):107- 23.

27. Fleuren MA, Paulussen TG, Van Dommelen $\mathrm{P}$, Van Buuren S. Towards a measurement instrument for determinants of innovations. Int J Qual Health Care. 2014;26(5):501-10.

28. M'Hamdi H I, van Voorst SF, Pinxten W, Hilhorst MT, Steegers EA. Barriers in the Uptake and Delivery of Preconception Care: Exploring the Views of Care Providers. Matern Child Health J. 2017;21(1):21-8.

29. Mazza D, Chapman A, Michie S. Barriers to the implementation of preconception care guidelines as perceived by general practitioners: a qualitative study. $B M C$ Health Serv Res. 2013;13:36.

30. Coll AS, Potter JE, Chakhtoura N, Alcaide ML, Cook R, Jones DL. Providers' perspectives on preconception counseling and safer conception for HIV-infected women. AIDS Care. 2016;28(4):513-8.

31. Goodfellow A, Frank J, McAteer J, Rankin J. Improving preconception health and care: a situation analysis. BMC Health Serv Res. 2017; 17(1):595.

32. Fehr KR, Fehr KD, Protudjer JL. Knowledge and use of folic acid in women of reproductive age. Canadian journal of dietetic practice and research : 2011;72(4):197-200. 